\title{
Development of 66kV Isolation Switch V Type Porcelain Column Fracture Insulation Protection Frame
}

\author{
Long $\mathrm{Li}^{1}$, Song Yang ${ }^{1}$, Pengfei Ren ${ }^{1}$, Liwei Zheng ${ }^{1 *}$, Yilin Wang ${ }^{1}$ \\ ${ }^{1}$ State Grid Jilin Electric Power Company Limited Baishan Power Supply Company, Baishan, Jilin,134300, China
}

\begin{abstract}
The mechanical strength of old $66 \mathrm{kV}$ disconnect switches (V-type porcelain column type) in outdoor substations has been affected by weather and daily operation for a long time, and the change of internal force of porcelain column caused by external force during open and closed circuit operation is very likely to cause porcelain column fracture, which poses a safety hazard to the safety of people and equipment.In order to ensure the safety of personal and equipment during operation and maintenance of the switch, this paper proposes a kind of insulation protection frame for $66 \mathrm{kV}$ disconnecting switch V-type porcelain column fracture. The simple structure, flexible operation, safety and reliability of this protective frame have been proved by practice that after using this protective frame in work, the efficiency of work is obviously improved and the safety of personal and equipment is effectively guaranteed.
\end{abstract}

\section{Introduction}

There are still a certain number of V-type porcelain column disconnect switches in the operating $66 \mathrm{kV}$ substations. Due to the quality of the product, the age of operation, the aging of the porcelain column, the influence of outdoor bad weather, and the wear and tear of long-term operation, many cases of porcelain column fracture have occurred, causing great safety hazards to people and equipment.

In response to the above problem, this paper proposes an insulation protection frame for $66 \mathrm{kV}$ disconnector switch V-post fracture. This insulating protective frame is designed according to the characteristics of the reversing operation of the site operator and the operation requirements of the $66 \mathrm{kV}$ disconnecting switch V-type porcelain column, combined with the safety distance between the human body and the $66 \mathrm{kV}$ live body during the operation of the operator. The developed protective device has been tested and verified to meet the requirements of various regulations and standards and various technical conditions for operating $66 \mathrm{kV}$ disconnecting switch V-type porcelain column, and has a simple structure, convenient construction, which is safe and reliable. $[1,2]$

\section{Insulation protection frame principle and structure}

\subsection{Design principles}

According to the characteristics of field operation and the operation requirements of $66 \mathrm{kV}$ isolation switch $\mathrm{V}$ porcelain column, combined with the operation of the human body and $66 \mathrm{kV}$ charged body in the operation of various types of safety distance, design both in line with various types of regulations, standard requirements and meet the operation of isolation switch $\mathrm{V}$ porcelain column of various technical conditions, simple and durable, convenient construction, safe and reliable protection device.

\subsection{Principle and structure}

Figure 1 shows a sketch of the structure of the insulated frame. The names of the parts are as follows: 1. epoxy resin tube insulation frame, 2. universal wheel, 3. silk net, 4. metal connection clamps.

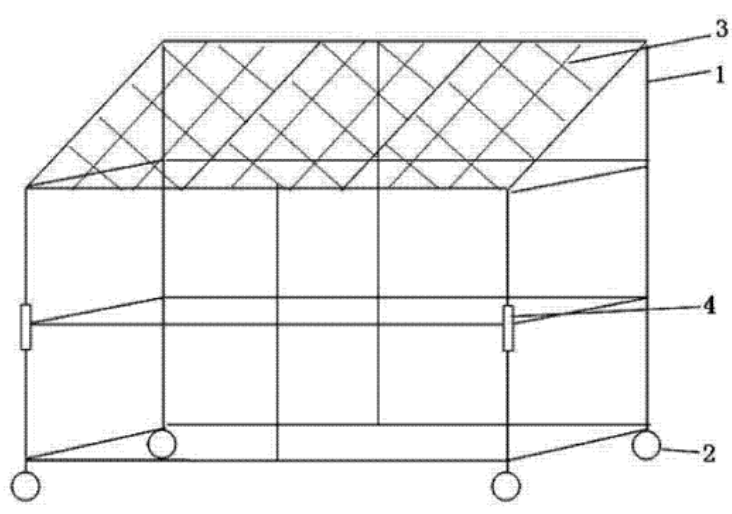

Fig. 1. Sketch of insulation protection frame structure

As shown in Fig. 1, the insulation protection frame of the isolation switch V-post fracture includes a desktop insulation frame composed of epoxy resin tubes, the main structure is simple, strong load-bearing, and the main body

\footnotetext{
* Corresponding author: 983720738@qq.com
} 
is made of epoxy resin tube insulation material, which can be decomposed for easy preservation and use. There are four universal wheels under the insulating frame, and the surface of the insulating frame has obliquely set silk net. $[3,4]$

The protection frame is used in combination of two docking (a single one in Figure 1), forming a type mesh table for easy catching, and the docking is connected with metal connecting clamps for easy fixing.

The universal wheels can support the whole insulated protective frame, which is convenient for the protective frame to move around the site. The silk net is made of insulating material to catch the falling switch when it breaks and falls to prevent discharge to the ground. Since the direction of fall after the isolation switch is broken is uncertain, so two "isolation switch type porcelain column broken insulation protection frame" need to be docked and used, and the docked two "isolation switch type porcelain column broken insulation protection frame" are fixed with metal connection clamps, which can also prevent The protective frame is prevented from being pushed down after the disconnecting switch breaks or falls. [4,5]

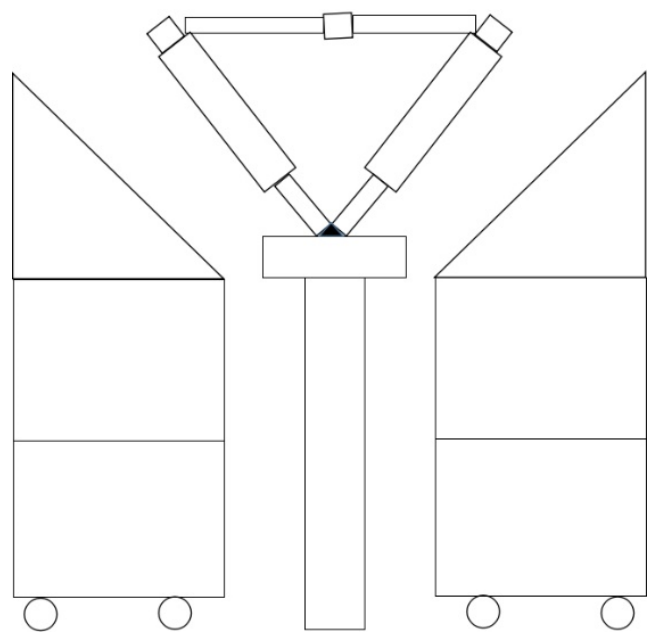

Fig. 2. Insulation protection frame and disconnect switch location diagram

\section{Advantages of insulated protective frame}

\subsection{The main structure is simple and practical}

epoxy resin insulation frame: the main structure is simple, strong load-bearing capacity, the main body is made of epoxy resin insulation material, the main body of the protection frame can be easily decomposed, colleagues are easy to save and use.

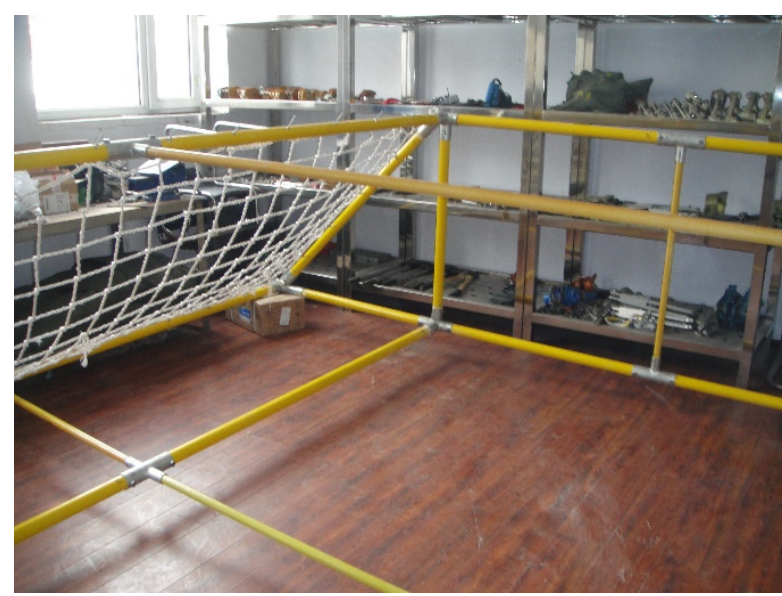

Fig. 3. Insulation protection frame physical assembly picture

\subsection{Easy transportation for on-site operations}

The bottom adopts universal wheels, which is convenient for transportation and can be moved freely according to the needs at the work site. Save time and effort, flexible and mobile.

\subsection{Economical and durable}

The protection main material is made of insulating material (silk net). Material price is suitable, durable, can withstand the weight of broken porcelain column, while insulation effect is better.

\subsection{Stable protection effect}

Isolation switch type porcelain column broken insulation protection frame need two pieces of butt use, using metal connection clamps. The safety factor is high.

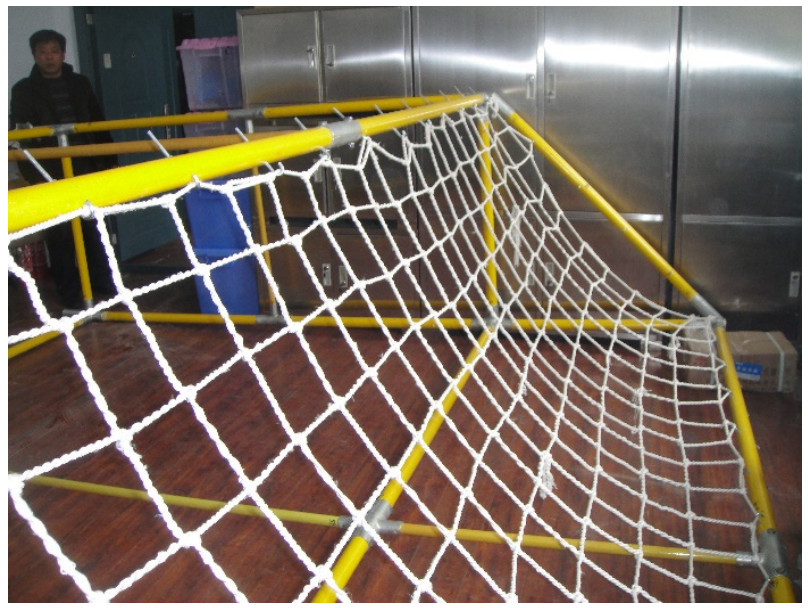

Fig. 4. Insulation protection frame protection net physical picture 


\section{The main technical characteristics of the protection frame}

\subsection{Main material}

The main body is made of epoxy resin $\Phi 50 \mathrm{~mm}, \Phi 30 \mathrm{~mm}$ insulating tube and $\Phi 10 \mathrm{~mm}$ silk insulating rope, the overall mass is lighter and meets both mechanical and insulating strength requirements.

\subsection{Transportation}

The overall protective frame is assembled with moving wheels at the bottom, which is convenient to install once and use flexibly for many times, and convenient for operating personnel to operate.

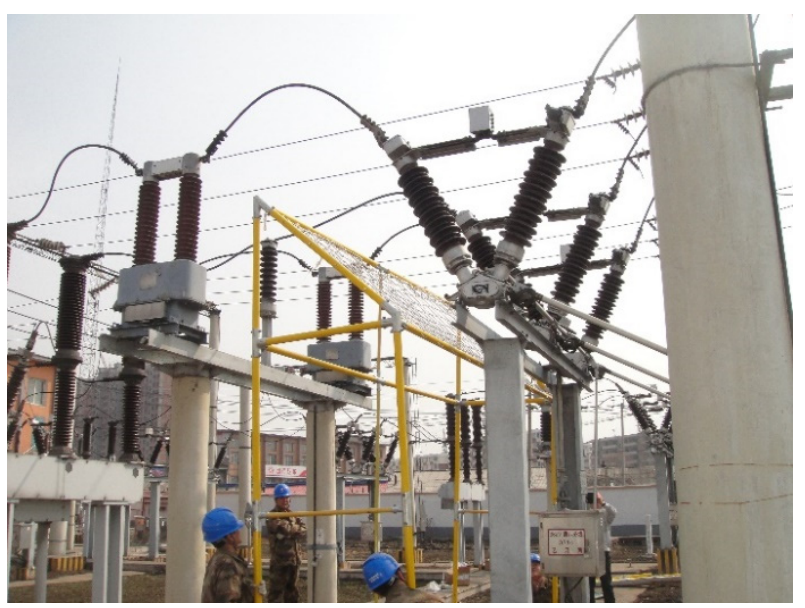

Fig. 5. Insulation protection frame operation site movement picture

\subsection{Universality}

The mounting position of the protective frame takes into account the versatility of different forms of disconnect switches and facilitates their use for other forms of disconnect switches

\subsection{Safety Effect}

Insulation protection frame in the protection of the operator from the porcelain column fracture to bring dangerous factors, but also to ensure that the porcelain column how to fracture to avoid falling to the ground after a single-phase short circuit or due to the diversion swing caused by the phase short circuit and further expansion of the accident hazard. [6]

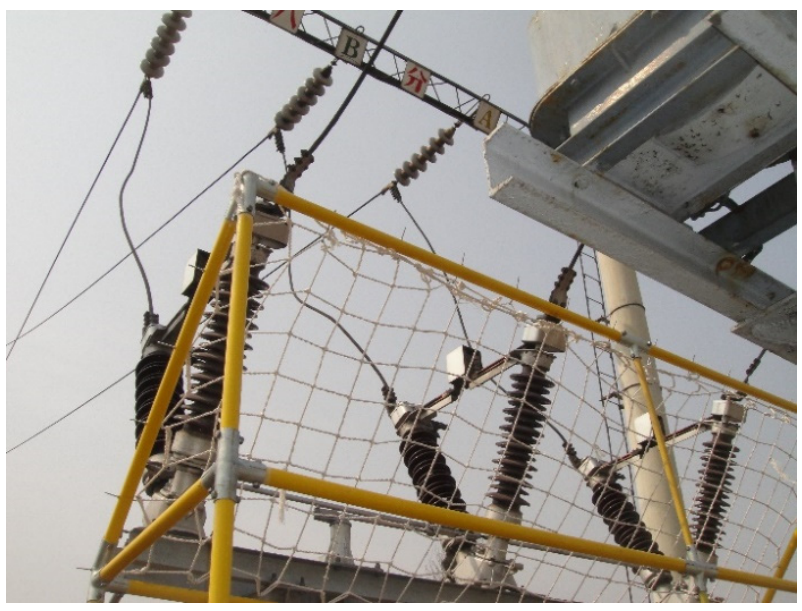

Fig. 6. Insulation protection frame field application effect picture

\section{Insulation protection frame all kinds of test results}

According to the electrical test standard of $66 \mathrm{kV}$ insulated tools specified in Q/GDW1799.1-2012, and the requirements of various safety distances, this insulated protective frame is tested and verified.

The following criteria were followed:

Q/GDW1799.1.2013 State Grid Corporation Electricity Safe Work Procedures for Power Transformation Part.

DL/T976-2005 Preventive test procedures for tools, devices and equipment for carrying out electrical work

DL/T972-2005/IEC61318:2003 Quality Assurance Guidelines for Tools, Devices and Equipment for Electricity Carrying Operations.

Q/ZGJ005-2002 Power substation operation regulations.

GB/T18037-2000 Basic technical requirements and design guidelines for tools for energized operation.

After the above test verification, this insulated protective frame meets all the standard requirements.

\subsection{Insulation pole frequency withstand voltage test}

$66 \mathrm{kV}$ insulated pole class test $175 \mathrm{kV}$ frequency withstand voltage per meter for 1 minute without overheating, flashover or breakdown.

\subsection{Insulation rope high voltage insulation test}

$66 \mathrm{kV}$ insulated rope type test every $0.5 \mathrm{~m}$ withstand $105 \mathrm{kV}$ high voltage test without overheating, flashover and breakdown. 


\subsection{Safe and effective distance requirements for insulated rod-type appliances}

The safe and effective distance of $66 \mathrm{kV}$ insulated poletype appliances is not less than $1.0 \mathrm{~m}$.

\subsection{Insulation rope class appliance safety effective distance requirements}

$66 \mathrm{kV}$ insulated rope-like appliances safe and effective distance of not less than 0.7 meters.

\subsection{Expert group acceptance opinions}

State Grid Baishan Power Supply Company organized the acceptance of the project "66kV isolation switch V-type porcelain column fracture insulation protection frame" on March 12, 2015. The acceptance team listened to the reports, examined the actual application and, after full and serious discussion, formed the following acceptance opinions.

The protective frame can meet the actual needs of field use, and the protection effect is remarkable. The test results prove that the device works reliably, is simple and easy to use, has a reasonable design and obvious economic benefits, has reached the domestic advanced level, and has good prospects for promotion and application.

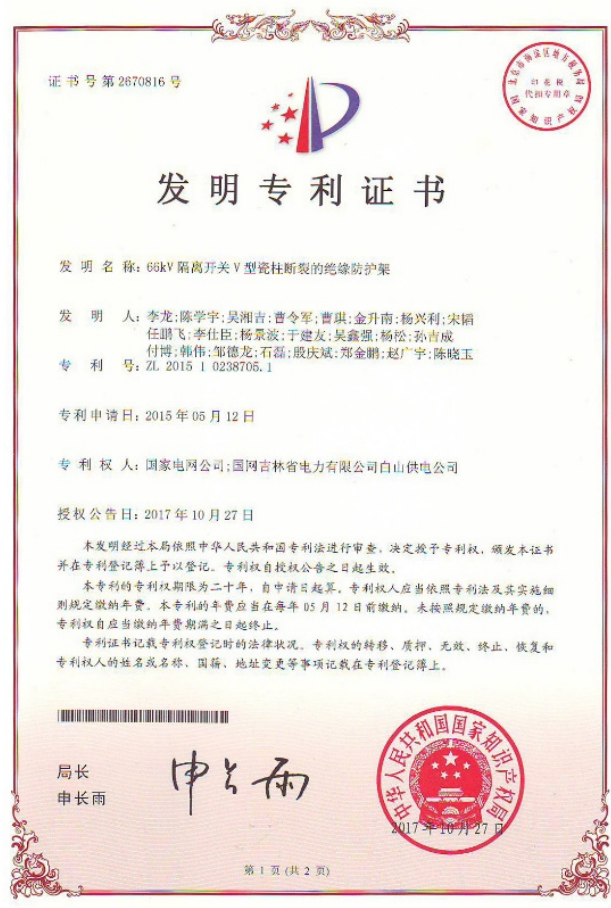

Fig. 7. 66kV disconnect switch V-type porcelain column fracture insulation protection frame obtained invention patent

\section{Applications and social benefits}

$66 \mathrm{kV}$ isolation switch V-type porcelain column fracture insulation protection frame is applied to Songjianghe $220 \mathrm{kV}$ substation. $66 \mathrm{kV} \mathrm{V}$ type porcelain column type isolation switch is simple, convenient, flexible and reliable to operate, replace and transform. A total of 40 sets of
$66 \mathrm{kVv}$-type porcelain column disconnect switches were replaced and operated 165 times. It ensured the personal safety of the operating personnel in the operation and reduced the safety hazards caused by the porcelain column breakage to the person and the equipment.

$66 \mathrm{kV}$ isolation switch V-type porcelain column fracture insulation protection frame is applied to Baishan $220 \mathrm{kV}$ substation. It makes the transformation and operation of $66 \mathrm{kVv}$-type porcelain column disconnect switches more simple, convenient, flexible and reliable. A total of 4 sets of $66 \mathrm{kVv}$-type porcelain column disconnect switches were replaced and operated 69 times. It ensured the personal safety of the operating personnel in the operation and reduced the safety hazards caused by the porcelain column breakage to the person and the equipment.

\section{Conclusion}

$66 \mathrm{kV}$ isolation switch $\mathrm{V}$ type porcelain column breakage insulation protection frame can ensure the safe distance between the operator and the charged body when the personnel operate, and ensure the safety of the person and equipment when the porcelain column breaks, the use of protection frame is simple, reliable, flexible and useful. It is simple, reliable and flexible when used. It is put into production to meet the actual needs of the site. It brings safety to the operation, overhaul and replacement of $66 \mathrm{kV}$ disconnect switches (V-type porcelain column type) and other forms of disconnect switches

\section{References}

1. Wang YJ, Zheng JF. Design and application of tooled protective frame for assembled concrete structures [J] Jiangsu Architecture,2020(S1):28-30.

2. Huang Jianxin. Improvement of the insulation protection of the circuit breaker of the handcart switchgear [J]. Electrical Engineering Technology, 2000(08):50.

3. Dong Longfeng, Sun Yanbo, Yan Mingwei, Xu Chang Nephew, Xin Wei. Research and application of tooled external protection frame in the construction of assembled buildings $[\mathrm{J}]$. Construction Technology Development, 2020,47(20):93-94.

4. Yang J. W. Design and application of insulating guards for 50-ton electric furnace cross-arm [J]. Equipment manufacturing technology, 2016(03):216217.

5. Shen Shaohao. Research and application of a new external protection system for the construction of assembled concrete structures $[\mathrm{J}]$. Building Construction, 2020,42(09):1680-1683.

6. Li Long; Jin Shengnan; Yang Xingli; Song Tao; Ren Pengfei; Li Shichen; Yang Jingbo; Yu Jianyou. Insulation protection frame for $66 \mathrm{kV}$ disconnect switch V-post fracture [P]. Chinese Patent: CN104810187A,2015-07-29. 